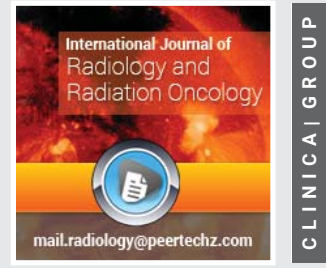

\section{Juvenile granulosa tumor of the ovary: Report of two cases}

\author{
Mohammed Lahfaoui*, Ahmed Azahouani, Mohamed \\ Belahcen and Houssine Benhaddou
}

Uro-Visceral Pediatric Surgery Service, Chu Mohammed Vi Oujda Morocco
Received: 24 April, 2020

Accepted: 03 June, 2020

Published: 04 June, 2020

*Corresponding author: Mohammed Lahfaoui, UroVisceral Pediatric Surgery Service, Chu Mohammed Vi Oujda, Morocco, E-mail: simo88_6@hotmail.com

Keywords: Granulosa tumour; Ovary; Child

https://www.peertechz.com

Check for updates

\begin{abstract}
Sex cord ovarian tumours are rare tumours that develop in non-germinal ovarian cells. The pathogenesis of these tumours remains undetermined and several cellular and molecular alterations may be involved in the development of juvenile granulosa cell tumours. The individualization of juvenile granulosa cell tumors has been a major advance in the treatment of these tumors in children over the past two decades. However, their natural history is reported in the literature and through a short and reliable series, prognostic factors have to be established. We report two cases of an 8 and 11 year old girl who presented with an abdomino-pelvic mass gradually increasing in size, on surgical exploration found a huge abdominal mass of the ovary. An anatomopathological study with immunostaining of the surgical specimen confirmed the diagnosis of a Juvenile granulosa cell ovarian tumor.
\end{abstract}

\section{Introduction}

Juvenile granulosa tumours are malignant tumours belonging to the group of sexual cord and stroma tumours, they are rare and represent less than $5 \%$ of ovarian tumours in children and adolescents, with a maximum frequency of between 0 and 10 years [1]. They have the particularity of being in the majority of secretory and hyperoestrogenic cases, and are considered to be tumours with low malignant potential. The ideal treatment for these tumours is surgical: adnexectomy [1-2].

\section{Case report 1}

An 8-year-old girl with no particular pathological history, had been suffering for about 15 days from pelvic pain, paroxysmal, of moderate intensity, associated with an increase in abdominal volume and unquantified weight loss. The abdominal examination found a painless abdominalpelvic mass measuring approximately $25 \times 20 \mathrm{~cm}$ in diameter, of hard consistency, poorly limited, mobile with respect to the superficial plane, and fixed with respect to the deep plane, with collateral venous circulation, without signs of hypersecretion and an undeplested umbilicus. The abdominal-pelvic ultrasound was performed, it revealed a large abdominalpelvic mass, occupying almost the totality of the abdomen, compatible with a supravesical cystic mass (Figure 1), associated with an intraperitoneal effusion of low abundance, without deep adenopathy, and without hepatic involvement.

An abdominal-pelvic Computed Tomography (CT) scan objectified a multicompartmentalized cystic mass, supraabdominal and left latero-vesical, which may correspond to a

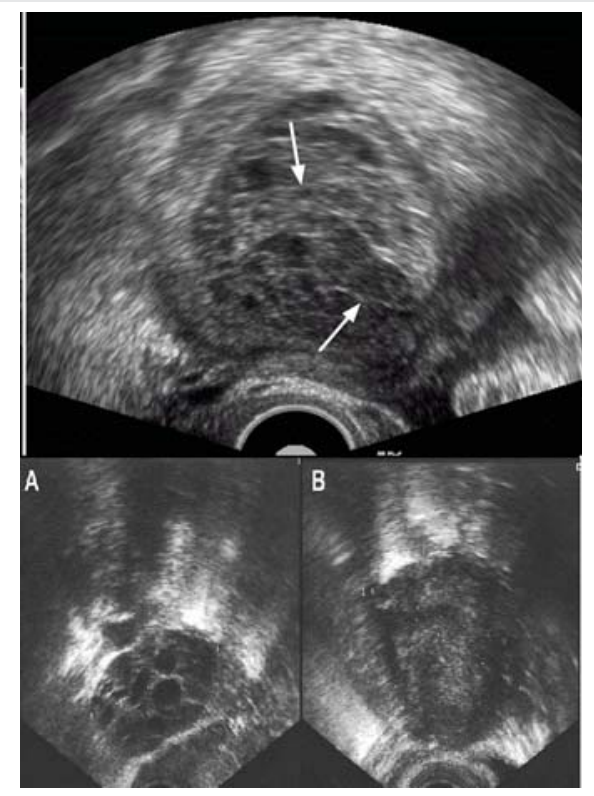

Figure 1: Ultrasound appearance of a multicompartmental cystic tumor. 
left ovarian cyst, a cystic formation of another nature cannot be ruled out (Figure 2). Tumor markers (Alpha-fetoprotein and beta HCG) were normal. Surgical exploration found a huge tumor at the left ovary (Figures 3,4) of $25 \times 20 \mathrm{~cm}$, with serum effusion. The girl has benefited from an ovarictomy with normal excisional borders on histological examination. The anatomo-pathological study completed by immunolabeling was returned in favour of a juvenile tumor of the granulosa.

The postoperative consequences were simple. The patient received periodic clinical and radiological monitoring through chest $\mathrm{x}$-rays and abdominal-pelvic ultrasound. This follow-up was without particularities. In a multidisciplinary staff it was decided that the patient would not require chemotherapy or radiotherapy.

\section{Case report 2}

An 11-year-old girl with no particular pathological history had been suffering for about 2 months from pelvic, paroxysmal,

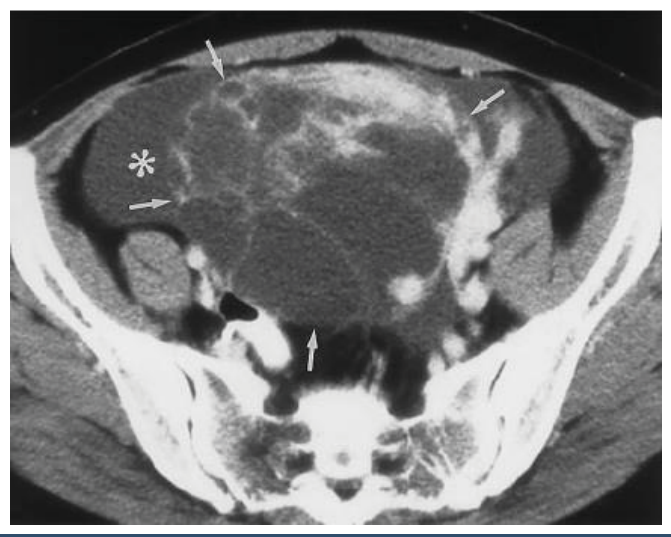

Figure 2: CT scan of the granulosa tumor

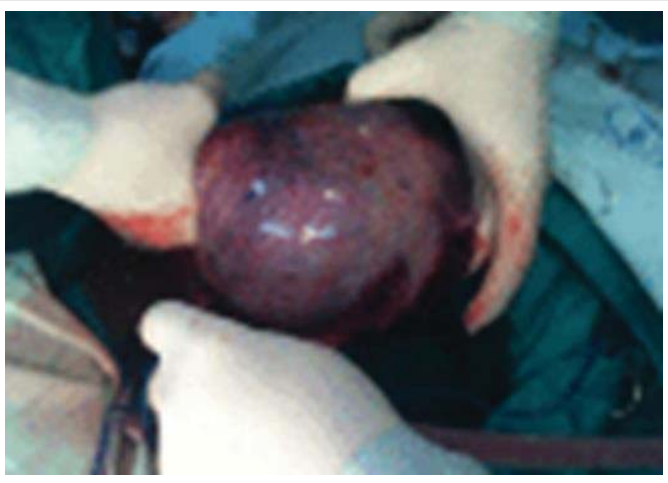

Figure 3: Intraoperative tumour.
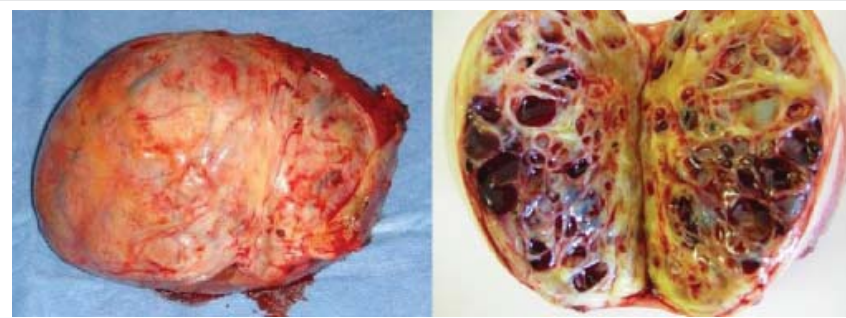

Figure 4: Removal mass. moderate intensity pain associated with an increase in abdominal volume without altering her general state of health. The abdominal examination found a painless abdominalpelvic mass measuring approximately $30 \times 20 \mathrm{~cm}$ in diameter, of hard consistency, poorly limited, mobile with respect to the superficial plane, and fixed with respect to the deep plane, with collateral venous circulation, without signs of hypersecretion and an undepressed umbilicus.

She had an ultrasound scan outside the UHC, which found a mainly echogenic mass, compatible with a supravesical cystic mass, without intraperitoneal effusion or deep adenopathies, and without liver damage. An abdominal-pelvic CT scan found this right lateral-uterine mass of $32 \times 21 \mathrm{~cm}$, tissue, semi-solid, cystic. The cystic component consisted of multiple stalls with strict, non-hematic fluid content; the solid portion was slightly elevated after injection. There was no deep endometriosis, no ascites, no adenomegaly and no uterine anomaly. The diagnosis of granulosa tumor was suspected. The patient was operated by laparoscopy, with a simple right cystectomy; the rest of the abdominal and pelvic intraoperative examination being normal. The histological examination concluded that the granulosa tumor did not cross the ovarian capsule within the limits of the examination (partial ovarian resection) but with excisional margins, justifying surgical reoperation with right adnexectomy, peritoneal biopsies and endo-uterine curettage. Final histological examination (Figure 5) concluded that the tumor was pT1a stage without tumor residue, the endometrium was of normal morphology and the peritoneal biopsies were free of any tumor proliferation. The multidisciplinary staff had decided on clinical-radiobiological surveillance (tumor markers: HAM and inhibin). This follow-up was without particularities.

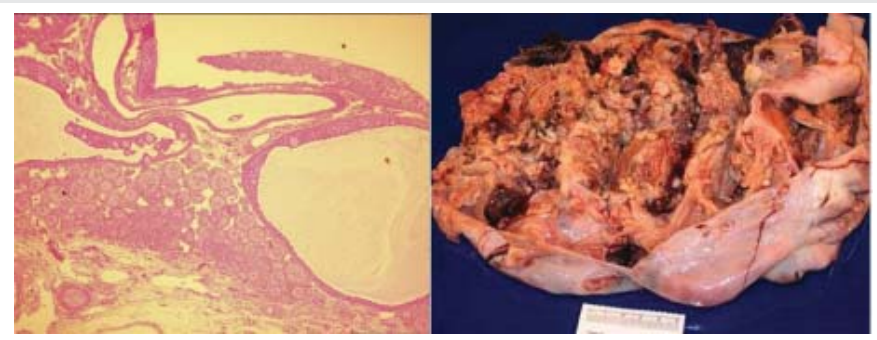

Figure 5: The predominantly cystic tumor consists of partially luteinized, proliferating granulosa cells, focused with a variable proliferation of theecal cells.

\section{Discussion}

Juvenile granulosa tumours are a particular anatomopathological entity that accounts for $5 \%$ of ovarian tumours in children and adolescents [1]. The juvenile form of granulosa tumours is diagnosed in patients under 20 years of age in $80 \%$ of cases, and under 10 years of age in $50 \%$ of cases, hence its name [2]. Several associations of juvenile granulosa tumours with more general pathologies have been reported; such as Olliers endochondromatosis, Maffucci syndrome, dysplastic anomalies [3]. Cellular and molecular alterations are involved in the development of TJG: role of growth factors and oncogenes, proliferation of granulosa cells induced by FSH 
and $\mathrm{G} \alpha \mathrm{s}$, anomaly in gene expression in gonadal determination [4]. Juvenile granulosa tumours are manifested by a tumor syndrome: painful abdominal distention related to tumor size [5].

Sometimes, the pain is acute, resulting from the twisting of the ovary and their hemorrhagic nature. Exceptionally, granulosa tumours may appear in the form of a rupture table with hemoperitoneum due to their hemorrhagic nature [1-5]. An endocrine syndrome is linked to the secretory functions of these tumours: early isosexual pseudo-puberty in young girls in case of estrogenic secretion; hirsutism, clitoral hypertrophy in case of androgenic secretion [6]. In the case of our patient, we found the abdominal-pelvic mass that was isolated, with no signs of hypersecretion.

Ultrasound is the most commonly used complementary examination for the exploration of ovarian tumours; it confirms the clinical examination data, links the pelvic mass to its ovarian origin, determines its semiological characteristics and evaluates the degree of abdominal-pelvic extension of the tumour. Ultrasound may reveal a large echogenic mass, or a cystic mass with partitions, achieving a multilocular aspect, but the unilocular aspect is also found, or it may appear of a pure solid homogeneous or heterogeneous nature [5].

CT has a detection rate that is sometimes lower than that of ultrasound, in the diagnosis of presumptive ovarian tumours. It could be justified in view of the large size of the pelvic tumour, which poses the problem of its primary site and its relationship with neighbouring anatomical structures [7]. The information provided by the MRI does not appear to be superior to that of a pelvic ultrasound performed under excellent technical conditions by an experienced ultrasound technician [7]. The ultrasound and CT scan performed on our patient identified the adnexal origin of a huge multi-partitioned cystic tumor (Figures 1,2). Estradiol is measured in early pseudo-puberty; it can be used as a tumor marker, while inhibin is currently a good marker specific for granulosa tumors [5].

The tumor is usually unilateral (97\%) and measures on average $12.5 \mathrm{~cm}$. Its surface is smooth, solid, cystic or a combination of both. It is characterized by dense ranges of cells with non-incised, hyperchromatic and often mitosis nuclei. Rare immature follicles secreting mucus are observed. Luteinization is common. The vimentin marker is positive in about $80 \%$ of cases [1-8]. These macroscopic and microscopic aspects were found in our case, with a high positivity of the anti-Vimentin antibody.
The ideal treatment for these tumours is surgical: adnexectomy. Chemotherapy is offered in case of recurrence in addition to surgical resumption, and must use at least one anthracycline $[9,10]$. Radiation therapy has not been shown to be effective $[9,10]$.

All our patients had an adnexectomy, without additional chemotherapy (Figures 3,4). Juvenile granulosa tumours are generally very good prognosis: $92 \%$ survival at 5 years $[9,10]$. The poor prognostic factors are: large size, ascites and capsular rupture [10].

\section{Conclusion}

Granulosa tumours are rare tumours of the ovary with an anatomo-pathological diagnosis. Several cellular and molecular alterations could be involved in the development of these tumours. Treatment typically involves initial surgery, which consists of an oophorectomy or salpingo-oophorectomy, and the prognosis is generally favourable.

\section{References}

1. Kalfa N, Philibert P, Patte C, Thibaud E, Pienkowski C, et al. (2009) Tumeurs juvéniles de la granulosa: expression Clinique et moléculaire. Gynécologie obstétrique et fertilité. 37: 33-44. Link: https://bit.ly/3el2UUT

2. Scully RE (1988) Juvenile granulosa cell tumor. Pediatr Pathol 8: 423-427.

3. Vaz RM, Turner C (1988) Ollier disease (enchondromatosis) associated with ovarian juvenile granulosa cell tumor and precocious pseudopuberty. $J$ Pediatr 8: 423-427. Link: https://bit.ly/3gHoNW6

4. Kim K, Lindstrom MJ, Gould MN (2002) Regions of $\mathrm{H}$ - and K-ras that provide organ specificity/potency in mammary cancer induction. Cancer Res 62 1241-1245. Link: https://bit.ly/3gNOZyr

5. Schumer ST, Cannistra A (2016) Granulosa cell tumor of the ovary. J Clin Oncol: 1180-1189. Link: https://bit.ly/3csYhfV

6. Calaminus G, Wessalowski R, Horms S, Gobel U (1997) Juvenile granulosa cell tumor of the ovary in children and adolescents: results from 35 patients registered in a prospective study. Gynecol Oncol 65: 447-452. Link: https://bit.ly/2Xrqsr8

7. Ardaens $\mathrm{Y}$, Coquel $\mathrm{P}$ (2000) Imagerie des kystes et des tumeurs de l'ovaire. EMC, Gynécologie 13P: 680-A-29.

8. Robert Kurman J (2019) 5ème Edition. Blaustein'n Pathology of the female genital tract $907-920$

9. Young RE, Dickersin GR, Scully RE (1984) Juvenile granulosa cell tumor of the ovary. Am J Surg Pathol 8: 575-596. Link: https://bit.ly/2XYNQvp

10. El Idrissi F, Ounejma S, Zeraidi N, Barhmi RS, Fadli A, et al. (1999) Tumeur de granulosa de l'ovaire à propos d'un cas. Médecine du Maghreb 76. Link: https://bit.ly/2BtcCw6

Copyright: ( 2020 Lahfaoui M, et al. This is an open-access article distributed under the terms of the Creative Commons Attribution License, which permits unrestricted use, distribution, and $\mathrm{r}$ eproduction in any medium, provided the original author and source are credited. 